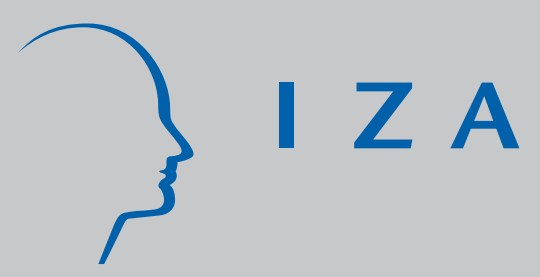

IZA DP No. 3535

Intergenerational Transmission of Healthy Eating Behaviour and the Role of Household Income

Alison Goode

Kostas Mavromaras

Murray Smith

J une 2008 


\title{
Intergenerational Transmission of Healthy Eating Behaviour and the Role of Household Income
}

\author{
Alison Goode \\ University of Melbourne \\ Kostas Mavromaras \\ University of Melbourne \\ and IZA \\ Murray Smith \\ University of Aberdeen
Discussion Paper No. 3535
June 2008 \\ IZA \\ P.O. Box 7240 \\ 53072 Bonn \\ Germany
Phone: +49-228-3894-0
Fax: +49-228-3894-180 \\ E-mail: iza@iza.org
}

\begin{abstract}
Any opinions expressed here are those of the author(s) and not those of IZA. Research published in this series may include views on policy, but the institute itself takes no institutional policy positions.

The Institute for the Study of Labor (IZA) in Bonn is a local and virtual international research center and a place of communication between science, politics and business. IZA is an independent nonprofit organization supported by Deutsche Post World Net. The center is associated with the University of Bonn and offers a stimulating research environment through its international network, workshops and conferences, data service, project support, research visits and doctoral program. IZA engages in (i) original and internationally competitive research in all fields of labor economics, (ii) development of policy concepts, and (iii) dissemination of research results and concepts to the interested public.
\end{abstract}

IZA Discussion Papers often represent preliminary work and are circulated to encourage discussion. Citation of such a paper should account for its provisional character. A revised version may be available directly from the author. 


\begin{abstract}

\section{Intergenerational Transmission of Healthy Eating Behaviour and the Role of Household Income*}

This paper investigates the possibility of intergenerational transmission of unhealthy eating habits from parents to adult children. It uses the 2003 Scottish Health Survey and estimates the association between the present healthy eating behaviour of adult children and the past parental death from cardiovascular disease (CVD). It uses parental CVD death as an adverse health signal which may cause a healthy eating compensatory response in adult children. This response is due to increased chances and perception of genetic predisposition of adult children as well as an indicator for parental past unhealthy eating habits which may have been passed onto the adult children. Regression analysis suggests that paternal history has no impact on either sons or daughters, and maternal history influences negatively the eating behaviour of daughters only. Unhealthy eating intergenerational transmission appears to be more intense amongst lower household income individuals.
\end{abstract}

JEL Classification: D1, I12, I18, J16

Keywords: intergenerational transmission, healthy eating, household income, cardiovascular disease, public health, gender

Corresponding author:

Kostas Mavromaras

Melbourne Institute

University of Melbourne

VIC 3050

Australia

E-mail:k.mavromaras@unimelb.edu.au

\footnotetext{
* This work forms part of the project PROGRESS 'An Economic Evaluation of the prevention of Adult Obesity in the UK' and is co-funded by the NPRI-MRC, UK, the Institute of Life Sciences, University of Aberdeen, UK and the Melbourne Institute, University of Melbourne, Australia. Goode and Mavromaras jointly assume first authorship of this paper. The UKDA supplied the data. The usual disclaimer applies.
} 


\section{Introduction}

Despite considerable efforts through public health promotions and the provision of primary care level advice, CVD morbidity in the UK remains high. There are no clear signs that current recommendations about lifestyle changes are adopted in any significant way by a sufficiently large proportion of the UK population (Kelly C. \& S.A. Stanner, 2003, Diabetes UK report 2007).

A familial history of cardiovascular disease (CVD) puts an individual at a higher risk of developing that disease themselves due to genetic factors. There are a number of behavioural factors which contribute significantly to an increased risk of developing CVD: the presence of obesity, unhealthy eating behaviour, low levels of physical activity and smoking, with or without a familial history of the disease. There are also a number of preventive behaviours, such as the use of aspirin and management of cholesterol levels, a healthy diet, exercising regularly and not smoking which can significantly reduce the risk of developing CVD, especially for those with a familial history (Renehan \& Howell 2005, McCusker et al. 2004).

How individuals perceive the risk to themselves of developing CVD appears to depend on a number of factors. Evidence suggests that individuals' perceptions of the familial risk of heart disease differs by age, gender, parental occupation, social class and whether one or both parents or close relatives have died from heart disease. Given a family history of heart disease, the risk may also be perceived differently by patients and clinicians. Individuals' perceptions of their own risk of developing chronic diseases will impact on their behaviour and lifestyles (Frich et al. 2006, Hunt et al. 2000, Watt et al. 2000, Walter et al. 2004). Studies from a range of disciplines suggest that there are intergenerational transfers of parental behavioural patterns to their children (Liefbroer \& Elzinga 2006). Studies show that particular lifestyle behaviours of children are strongly influenced by the behaviour of their parents, and these influences carry through into their adult lives, after they have left the parental home. For example, a number of studies on smoking suggest that there is a strong association between parental smoking and the uptake of smoking by children, young adolescents and their smoking habits in adulthood (Kalesan 
et al. 2006, Szabo et al. 2006, Wen et al. 2005, Bantle \& Haisken-DeNew 2002). There is further evidence that behavioural intergenerational transmissions can be gender-related. For example, maternal smoking is shown to have a strong influence on girls' smoking decisions, while paternal smoking habits are transmitted primarily to their sons (Loureiro et al. 2006). Similarly, familial determinants have also been shown to influence children's eating habits and diet quality (Patrick \& Nicklas 2005, Brown \& Ogden 2004, Matteucci et al. 2005). As with smoking, there is also evidence suggesting that as young adults, daughters are more influenced by the maternal behaviour and sons by the paternal behaviour (Baker et al. 2000). Mothers exert relatively high levels of control over food intake of their children and they make more of an effort with daughters than sons to ensure they do not put on weight (Tiggemann \& Lowes 2002).

The frequency and everyday nature of mealtimes and other eating occasions may well offer a particularly potent source of early inter-generational transmission of eating attitudes and beliefs. Evidence suggests that familial habits act on family resemblance in both absolute and relative breakfast energy intakes (Billon et al. 2002). The degree of parental control exerted over child-feeding provides a potential behavioural mechanism by which parental attitudes and beliefs get transmitted to children and it would seem to confirm the consensus that parental/family habits influence the later dietary and other habits of adult children. Lastly, certain types of behaviour are associated with sociodemographic factors. For example, a higher socioeconomic status is associated with more restrictive dietary practices and more vigorous physical activity being reported (Wardle et al. 2001). ${ }^{1}$ There is evidence that behaviour related to the choice, acquisition and preparation of food for the family today still remains principally in the hands of the female members of a large majority of families (Australian Social Trends 2001, Bond \& Sales 2001, Bateman \& Munro 2006). This suggests that intergenerational transfers of healthy eating behaviour and attitudes may limit themselves to the female members of families.

\footnotetext{
${ }^{1}$ For an informative exposition of the literature of cultural intergenerational transfers affecting labour market and other types of economic behaviour see Farre \& Vella (2007).
} 
This study investigates whether intergenerational transfers influence the lifestyles of adult children, with particular reference to the potential influence of parental health and parental behaviour in the past on current healthy eating of adult children. ${ }^{2}$

The paper is structured as follows. The next section sets out the method and the data used. It explains how a number of testable hypotheses are formulated and tested. Section 3 presents the estimation results and discusses them. Section 4 concludes. An appendix contains further detail on the data.

\section{Method and data}

Possible healthy eating responses of adult children to parental CVD death

The paper concentrates on the degree to which the cause of death of a parent by CVD may be associated with the presence of healthy eating in adult children, by distinguishing between genetic and behavioural intergenerational transmission of CVD risk.

Observed intergenerational transmission of CVD risk will depend on the share between the two possible routes, the genetic and the behavioural one. The genetic route will work in a clearly predictable direction (those with parents who have developed CVD are more likely to develop CVD themselves), but to a varying degree. Take the two limiting cases of adult children who have experienced a parental CVD death: (i) At the one extreme will be those whose parental CVD death was due exclusively to the unhealthy eating habits of the parents and where no genetic predisposition will be present. If the adult children do not carry the unhealthy parental habits, then these children will grow older subject to the average risk that corresponds to their other characteristics. (ii) At the other extreme will be those whose parental CVD was due exclusively to a bad genetic draw (for the sake of argument assume that the adult children can recall perfectly that their parents followed very healthy lifestyles), then the adult children of these parents know that they can count on an above average likelihood of developing CVD problems as they grow older. Reality will in most cases lie somewhere in the middle.

\footnotetext{
${ }^{2}$ This study does not set out to understand exactly how such intergenerational transfers may operate, as it has no data source that could support such a complex investigation.
} 
The occurrence of a parental CVD death will send a strong health signal to the adult children, in that they are more likely to be genetically predisposed to CVD themselves than their counterparts who have not experienced a parental CVD death. The direction of the response of the adult children in terms of their lifestyles can only be in one direction: they can only aim to improve their lifestyles in order to compensate for the information that they are subject to above average CVD risk. There are many such compensatory responses that may be followed: this paper concentrates on compensating through improvements in healthy eating. ${ }^{3}$ Other things equal, the extent of any compensatory lifestyle response can be expected to be at its strongest for those who know their parents to have led a healthy life, thus giving them grounds to the expectation that they too could be subjected to the same unfavourable genetic draw as their parents. In the context of survey data, adult children with parental CVD death history will be recorded in the data with healthier eating habits than the average survey respondent if they are subject to a compensatory response of improved healthy eating. ${ }^{4}$

In addition to the health signal to the adult children that a parental CVD death may generate, it also provides the researcher with a crucial distinction regarding the healthy eating habits of the parents. In a purely physiological way it is safe to assume that unhealthy eating habits lead to a higher probability of an earlier CVD death. Hence, when we compare parents who have died of CVD with the remaining parents in the sample (who have either died of other causes or have not died yet) we can safely assume that the parents who died of CVD are more likely to have followed (CVD-death causing) lifestyles than the average parent, including unhealthy eating habits. Therefore, when we observe the adult children whose parents have died of CVD, we are in essence observing the adult children that have been brought up by parents with unhealthier than average eating habits. Hence, if there is any intergenerational transmission of lifestyles we could expect that, other things equal, adult children whose parents died of CVD will have worse

\footnotetext{
${ }^{3}$ Estimations control for other health related lifestyles such as smoking and drinking.

${ }^{4}$ Note that irrespective of how adult children perceive parental lifestyles, it is clear to an adult child that healthier eating will reduce the chances of future CVD problems, it will just do more so in the case of genetically predisposed adult children, than in the case of parental CVD deaths that were clearly due to unhealthy eating habits. In practice, both reasons will be present to a varying degree that is however unobserved by our data.
} 
lifestyles, including unhealthy eating habits, and will be more likely to follow the footsteps of their parents and develop CVD problems as they grow older. In the context of survey data, adult children with parental CVD death history will be recorded in the data with less healthy eating habits than the average survey respondent if they are subject to intergenerational transmission of bad habits.

The empirical question and the resulting testable hypothesis that arise can be formulated as follows. Other things equal, we would expect the adverse health signal of a parental CVD death to generate a compensatory response in the adult children in the direction of healthier lifestyles. One such compensatory response could be healthier eating. At the same time, we can expect that, if intergenerational transmission of unhealthy lifestyles is present, the signal of a parental CVD death would help us identify those who are more likely to have been subjected to such transmissions and as a consequence have worse lifestyles themselves, including unhealthier eating. Note that the two effects run in the opposite direction in that if a compensatory response follows a parental CVD death we should observe better lifestyles, while if intergenerational transmission are at play we should observe worse lifestyles.

It is not possible to determine a priori whether the positive compensatory response (adult children with higher risks will eat healthier in a preventive way) or the negative intergenerational transmission response (unhealthy eating habits of parents continue to be assumed by adult children) will prevail at the population level, as both effects are as plausible as one another. Intuition would suggest that both compensatory behaviour and intergenerational transmission will coexist and that what we observe in survey data will be the net outcome of the two opposite effects. The answer to this question is an empirical issue and this paper sets out to estimate the net outcome of these behaviours.

\section{Data Description}

This paper uses data from the 2003 Scottish Health Survey (SHS) in order to test the intergenerational transmission of healthy eating behaviour. The paper uses multivariate regression in order to control for a number of pertinent covariates such as age, education and other. It uses observations on parental deaths from CVD against all other death 
causes and estimates their association with the healthy eating behaviour of adult children. The SHS contains information on people living in a random selection of private households in Scotland. All persons aged 13 and over within selected households were interviewed. All interviews were done using computer assisted interviewing and they were followed by a nurse visit. Children aged 13-15 were included in the sample and were interviewed via an adult. The survey collected information on food frequency variables, smoking, physical activity, alcohol consumption, along with a range of sociodemographic information and medical information.

This paper estimates the association between healthy eating and a number of sociodemographic and economic factors. The data contains information on whether the cause of death of a natural parent was reported to be either (i) CVD (defined as any of the following: high blood pressure, angina, heart attack, stroke, other heart trouble) or (ii) any other reason. Around 56 percent of the survey respondents had experienced the death of a parent and just over 40 percent of these deaths were caused by CVD.

For the purposes of the present analysis, individuals were included in the sample if they were aged 16 - 64 when interviewed. After excluding those who were currently pregnant and those who had provided no information on height and/or weight, a sample of 4,791 individuals was analysed, representing 77 percent of all those in the survey between the age range of $16-64$.

A healthy diet is constructed by using a scoring system developed by the Lanarkshire Health Board, Scotland, UK. Five healthy foods (fruit, vegetable, fish, poultry and potatoes (not chips)) and five less healthy foods (chips, crisps, confectionary, biscuits and soft drinks) are selected. Respondents are awarded a score between 0 and 3 , in accordance with the self-reported frequency of consumption of each of the ten foods, $0=$ least healthy, $3=$ healthiest. Individual food type scores are then added together resulting in a final score for overall healthy diet, ranging between 0 (least healthy) and 30 (most healthy).

Central for the analysis in this paper is the information on the cause of parental death of all interviewees. There is separate information about paternal and maternal deaths. All 
respondents are asked if they have experienced a parental death and if they answer yes for either their father or their mother they are given two categories of causes which are:

(i) Death due to hypertension, angina, myocardial infarction, stroke, other heart trouble, or

(ii) Death due to other than the above conditions

The main empirical objective of this paper is to study the relationship between present healthy eating and parental death experience of survey respondents, making the explicit distinction between different causes of parental death. The hypothesis this paper wants to test is whether the experience of parental death caused by CVD reasons has had any longterm impact on the healthy eating behaviour of the adult offspring.

In order to link the data with the regression analysis that follows some of its specific features have to be pointed out. Note that the data reports incidences of parental death that have preceded the date of the data collection (some time before 2003, but we do not know when). It also reports the healthy eating habits of the adult children at the date of the data collection (which we know is in the year 2003). It is, therefore, reasonable to expect that a large proportion of those respondents who have experienced a parental CVD-death will have had enough time to have responded to a parental CVD death with a change in their eating behaviour.

This paper has made two arguments which can be tested using this data. First, if there is to be a healthy eating compensatory response by the adult child to a parental CVD-death, this would have to be through switching to healthier eating. Any such compensatory response may vary in strength depending on how the adult child assesses the risk of genetic predisposition. Note that some of the healthy eating responses of adult children after a parental CVD-death would have been short-lived and some long-lived. Although it is sensible to assume this, we cannot observe it in our data. Given the nature of our data, we will not be able to observe but a few of the short-lived responses as by the time we observe the respondents most of these responses will have been reversed. What we observe is the long-run average healthy eating position of the survey respondents. We can therefore interpret the observed healthy eating behaviour of those who have not 
experienced a parental CVD-death as having had no health signal to respond to by way of compensatory healthy eating, and those who have experienced a parental CVD-death as having had the time to (i) incorporate any successful long-term healthy eating compensatory behaviour responses and to (ii) have already reversed most of their short lived healthy eating behaviour responses. It is in the light of this distinction between those who have and those who have not experienced a parental CVD-death that this paper interprets the estimates of the association between CVD-death and healthy eating behaviour in the regression analysis that follows.

Note that although the data provides no information regarding the lifestyles of the parents, we have established that parents with unhealthy lifestyles are more likely to be amongst the parents who suffered CVD death. Hence, if there has been any intergenerational transmission of eating habits, we would expect that (other things equal) the adult children who experienced a parental CVD death will have worse eating habits themselves. Both these hypotheses can be tested using the data presented here.

\section{Regression analysis and results}

We use the method of Ordinary Least Squares and we estimate separately for men and women the associations between Healthy Eating and the different types of Parental Cause of Death in the presence of a number of control factors. We have carried out two sets of estimations using two different samples in order to confirm the robustness of our results to the selection of the appropriate sample. The first sample uses all observations including those who have not experienced a parental death. For this sample, the variable CVD-death is defined against a reference category of either having experienced a nonCVD death or not having experienced a parental death at all. The second sample excludes all those who have not experienced a parental death at all and uses the variable CVDdeath with the reference category being those who have experienced a non-CVD death. This implies that the first sample contrasts the behaviour of those with parental CVD death against a mixed reference group (with non-CVD death and without death) and the second sample contrasts the behaviour of those with parental CVD death against those with all other parental deaths. 
TABLE 1: Healthy Eating regression results

\begin{tabular}{|c|c|c|c|c|c|c|c|c|}
\hline & \multicolumn{4}{|c|}{ Full sample } & \multicolumn{4}{|c|}{ Reduced sample } \\
\hline & \multicolumn{2}{|c|}{ Men } & \multicolumn{2}{|c|}{ Women } & \multicolumn{2}{|c|}{ Men } & \multicolumn{2}{|c|}{ Women } \\
\hline & Coeff. & t-ratio & Coeff. & t-ratio & Coeff. & $t$-ratio & Coeff. & t-ratio \\
\hline Constant & 12.05 & 23.55 & 13.77 & 30.99 & 12.02 & 10.50 & 15.29 & 13.96 \\
\hline \multicolumn{9}{|c|}{ Age group (reference category age less than 25) } \\
\hline 25 to 34 & 2.14 & 5.15 & 1.04 & 2.89 & 1.82 & 1.57 & -0.45 & -0.42 \\
\hline 35 to 44 & 3.44 & 8.42 & 1.90 & 5.35 & 2.63 & 2.51 & 0.50 & 0.50 \\
\hline 45 to 54 & 4.25 & 9.41 & 3.14 & 8.44 & 3.73 & 3.52 & 1.55 & 1.57 \\
\hline 55 to 64 & 5.30 & 10.88 & 4.24 & 10.44 & 4.83 & 4.46 & 2.75 & 2.73 \\
\hline \multicolumn{9}{|c|}{ Education (Reference category lowest education) } \\
\hline Higher & 2.93 & 9.74 & 3.18 & 12.46 & 2.29 & 5.68 & 3.24 & 10.42 \\
\hline Upper-middle & 1.42 & 4.82 & 2.24 & 6.81 & 1.06 & 2.82 & 1.96 & 4.39 \\
\hline Lower-middle & 1.58 & 4.36 & 1.66 & 5.56 & 0.70 & 1.25 & 1.56 & 3.84 \\
\hline Low & 0.61 & 1.90 & 0.76 & 2.92 & 0.77 & 1.58 & 1.17 & 3.33 \\
\hline \multicolumn{9}{|l|}{ Family } \\
\hline Dep. children & -0.06 & -0.51 & -0.28 & -2.80 & 0.04 & 0.21 & -0.33 & -2.11 \\
\hline Married or co-hab & -0.22 & -0.73 & 0.77 & 2.89 & -0.40 & -0.83 & 0.86 & 2.11 \\
\hline $\begin{array}{l}\text { Divorced or sep. } \\
\text { Economic status }\end{array}$ & 0.23 & 0.48 & 0.86 & 2.70 & 0.21 & 0.33 & 0.87 & 1.93 \\
\hline In Employment & -0.71 & -2.77 & -0.58 & -2.95 & -0.48 & -1.34 & -0.55 & -2.04 \\
\hline Household income & 0.02 & 2.55 & 0.02 & 4.01 & 0.02 & 1.61 & 0.01 & 3.03 \\
\hline \multicolumn{9}{|l|}{ Health and Lifestyles: } \\
\hline \multicolumn{9}{|c|}{ Smoking (reference category never smoked) } \\
\hline Never Smoked & 1.23 & 5.18 & 1.24 & 5.87 & 1.92 & 5.53 & 1.54 & 5.24 \\
\hline Ex-smoker & 1.82 & 6.62 & 1.34 & 5.59 & 1.92 & 5.32 & 1.34 & 4.16 \\
\hline \multicolumn{9}{|c|}{ Alcohol drinking (reference category regular drinking below the limit) } \\
\hline Regular over limit & -0.20 & -0.85 & -0.001 & -0.001 & -0.33 & -1.02 & -0.59 & -1.71 \\
\hline No alcohol & -0.78 & -3.26 & -0.93 & -5.03 & -0.76 & -2.27 & -1.06 & -4.25 \\
\hline Physical Activity & 0.04 & 4.03 & 0.06 & 5.39 & 0.05 & 3.19 & 0.06 & 3.40 \\
\hline General Health & -0.24 & -2.00 & -0.22 & -2.06 & -0.06 & -0.36 & -0.26 & -1.91 \\
\hline \multicolumn{9}{|l|}{ Parental CVD death } \\
\hline Father CVD-death & 0.24 & 0.95 & 0.12 & 0.54 & 0.23 & 0.83 & 0.16 & 0.68 \\
\hline Mother CVD-death & 0.27 & 0.95 & -0.71 & -2.83 & 0.30 & 1.00 & -0.69 & -2.68 \\
\hline R-square & 0.2 & & 0.2 & & 0.1 & & 0.2 & 48 \\
\hline Sample size & 21 & & 26 & & 11 & & 14 & \\
\hline
\end{tabular}

Note: Dependent variable is healthy eating score. Ordinary least squares estimation was performed using STATA. Robust standard errors have been used to calculate t-ratios. Full sample includes all respondents. Reduced sample excludes those who have not experienced a parental death (caused by CVD or other).

As shown in Table 1, the coefficients of the variable CVD death are very similar between the two samples. This is a clear indication that the choice of reference category in the analysis does not influence the results so that there is no need for further modelling to distinguish between the two different reference categories. 
The estimation controls for a number of factors that may be associated with the level of healthy eating in several ways. These include age, education, marital status, number of dependent children, employment status and household income, smoking and alcohol drinking, general health level and physical activity level and are all defined in the Appendix.

Age is negatively associated with Healthy Eating in that particularly younger men eat less healthy food. The Healthy Eating score for both men and women is higher for those with more education. The number of dependent children in a household is not associated with the average Healthy Eating of men, but is negatively associated with that of women. Being married or co-habiting is positively associated with healthy eating for women with no significant association detected for men. A similar result appears for divorced or separated men and women.

Being in Employment is negatively associated with healthy eating for both men and women, whilst men and women in higher income groups eat more healthy food. There is a positive association between presently smoking and less healthy eating when contrasted with ex smokers and those who never smoked. Those who report regular physical activity eat healthier and those who drink no alcohol at all eat moderately less healthy than those who drink in moderation. Those who report a better health level also report less healthy eating, but the association is not strong and the direction of causality cannot be established.

\section{Parental CVD death and eating behaviour}

There is no association between healthy eating and the cause of either maternal or paternal CVD-death for men. ${ }^{5}$ There is no association between healthy eating and the cause of paternal CVD-death for women. There is a statistically significant negative association between healthy eating and the cause of maternal CVD-death for women.

\footnotetext{
${ }^{5}$ For the CVD death estimates to be interpreted precisely, it is crucial to remember that they represent the combined effect of the compensatory response to a CVD death and the effect of the intergenerational transmission of unhealthy eating habits which will have opposite signs. The data does not allow us to estimate these effects separately, so that a zero coefficient could conceptually be the result of two opposing strong effects, or no effects at all.
} 
Note that results are not affected by the choice of the CVD-death reference category. This is particularly so regarding the result of women and maternal CVD-death.

This result suggests that there is indirect but nonetheless clear and convincing evidence of intergenerational transmission of unhealthy eating habits from mothers to daughters. ${ }^{6}$ Daughters are more likely to have absorbed unhealthy maternal eating habits than sons during their childhood years, and daughters are also more likely to be in a position to practice these habits in their adult years as women.

\section{The role of household income}

An important aspect in both health behaviours and intergenerational transmissions is the potential impact of household income. In general higher income facilitates the transmission of beneficial behaviours. We test this in the context of CVD-death and healthy eating using a direct measure of reported household income which has been equivalised to account for household characteristics and needs. Equivalised income is a measure that reflects actual consumption possibilities better than gross or net income. Results in Table 1 have already indicated that income in itself is positively associated with healthy eating, that is people with more money will, ceteris paribus, eat healthier. Note that the question that we want to ask here, however, is different. We want to know if the direction and strength of the intergenerational transmission in eating behaviours that has already been estimated, may differ by the level of household income. To do this we introduce an interaction variable which is the product of the income and CVD death variables. Table 2 presents the extended models. None of the other control variables has been changed so that results can be directly compared.

Table 2 shows clearly that the associations between CVD death and healthy eating behaviour for fathers and both sons and daughters and for mothers and sons remain insignificant irrespective of the income levels of the household. The inclusion in the estimation of the interaction terms leaves the significance of the CVD-death variables unaltered.

\footnotetext{
${ }^{6}$ Regressions were carried out to investigate the degree to which similar transmissions can be traced in smoking behaviour, but none were found.
} 
The interaction between income and CVD-death exceeds the 10 percent significance level for the full sample and gets very close to the 5 percent significance level in the case of transmission from mothers to daughters. The significance of the interaction between income and maternal CVD death suggests that the negative association between healthy eating and maternal CVD death becomes smaller for higher income households.

TABLE 2: Intergenerational transmission and household income

\begin{tabular}{|c|c|c|c|c|c|c|c|c|}
\hline & \multicolumn{4}{|c|}{$\begin{array}{l}\text { Model 1: without an income } \\
\text { interaction term }\end{array}$} & \multicolumn{4}{|c|}{$\begin{array}{l}\text { Model 2: with an income } \\
\text { interaction term }\end{array}$} \\
\hline & \multicolumn{2}{|c|}{ Full sample } & \multicolumn{2}{|c|}{ Reduced sample } & \multicolumn{2}{|c|}{ Full sample } & \multicolumn{2}{|c|}{ Reduced sample } \\
\hline & Men & Women & Men & Women & Men & Women & Men & Women \\
\hline Household Income & $\begin{array}{c}0.02 \\
(2.55)\end{array}$ & $\begin{array}{c}0.02 \\
(4.01)\end{array}$ & $\begin{array}{c}0.02 \\
(1.61)\end{array}$ & $\begin{array}{c}0.01 \\
(3.03)\end{array}$ & $\begin{array}{c}0.02 \\
(3.41)\end{array}$ & $\begin{array}{c}0.02 \\
(3.55)\end{array}$ & $\begin{array}{c}0.03 \\
(2.77)\end{array}$ & $\begin{array}{c}0.01 \\
(1.98)\end{array}$ \\
\hline Father CVD-death & $\begin{array}{c}0.24 \\
(0.95)\end{array}$ & $\begin{array}{c}0.12 \\
(0.54)\end{array}$ & $\begin{array}{c}0.23 \\
(0.83)\end{array}$ & $\begin{array}{l}0.16 \\
(0.68)\end{array}$ & $\begin{array}{c}0.56 \\
(1.17)\end{array}$ & $\begin{array}{c}0.35 \\
(1.12)\end{array}$ & $\begin{array}{c}0.71 \\
(1.39)\end{array}$ & $\begin{array}{c}0.26 \\
(0.79)\end{array}$ \\
\hline Mother CVD-death & $\begin{array}{c}0.27 \\
(0.95)\end{array}$ & $\begin{array}{c}-0.71 \\
(-2.83)\end{array}$ & $\begin{array}{c}0.30 \\
(1.00)\end{array}$ & $\begin{array}{l}-0.69 \\
(-2.68)\end{array}$ & $\begin{array}{c}0.40 \\
(0.82)\end{array}$ & $\begin{array}{l}-1.22 \\
(-2.98)\end{array}$ & $\begin{array}{c}0.42 \\
(0.82)\end{array}$ & $\begin{array}{l}-1.29 \\
(-3.05)\end{array}$ \\
\hline $\begin{array}{l}\text { Income*Father } \\
\text { CVD-death }\end{array}$ & - & - & - & - & $\begin{array}{l}-0.012 \\
(-0.76)\end{array}$ & $\begin{array}{l}-0.009 \\
(-1.23)\end{array}$ & $\begin{array}{l}-0.019 \\
(-1.11)\end{array}$ & $\begin{array}{l}-0.004 \\
(-0.50)\end{array}$ \\
\hline $\begin{array}{l}\text { Income*Mother } \\
\text { CVD-death }\end{array}$ & - & - & - & - & $\begin{array}{l}-0.005 \\
(-0.36)\end{array}$ & $\begin{array}{l}0.022 \\
(1.73)\end{array}$ & $\begin{array}{l}-0.005 \\
(-0.34)\end{array}$ & $\begin{array}{r}0.026 \\
(1.94)\end{array}$ \\
\hline Sample size & 2161 & 2630 & 1174 & 1430 & 2161 & 2630 & 1174 & 1430 \\
\hline R-square & 0.2336 & 0.2514 & 0.1715 & 0.2348 & 0.2341 & 0.2523 & 0.1766 & 0.2367 \\
\hline
\end{tabular}

Note: Dependent variable is healthy eating. OLS coefficients reported with t-ratios underneath them in italics. All other control variables in Table 1 have also been included in the regression. Sample sizes are also the same as in Table 1. Detailed results for Model 2 (with interaction terms) are presented in Table A2 in the Appendix.

It should be noted that the strong statistical significance of the direct associations between maternal CVD death and daughters healthy eating on the one hand and maternal CVD death and income on the other hand both remain unaffected by the inclusion of the interaction term in the estimation. Simply put, to the degree that results in this paper can be interpreted as evidence for the presence of intergenerational transmission of unhealthy eating habits, the interaction term in Table 2 suggests that there is weak statistical evidence that this transmission is more intense amongst lower income households than 
higher income households. A number of similarly constructed interaction terms were tried out in order to reflect other possible transmission routes such as through education, socioeconomic deprivation and employment status differences, but none was found to be statistically significant. ${ }^{7}$ This clearly points towards present income and the consumption levels and quality it enables as a factor that matters in healthy eating intergenerational transmission.

The robustness of the model and the results

Apart from estimating using two different samples, a number of alternative model specifications have been estimated in order to test for the sensitivity of the CVD death results. The inclusion or exclusion of variables such as general health status, BMI and other did not generate a discernible change in the CVD-death results. We introduced information on premature death of parents (defined as before the age of 65) and this too did not make a difference. Although the reporting of CVD death cannot in itself lead to healthy eating reporting bias, it should be noted that reporting bias (in the form of reporting better healthy eating by those with the worse behaviour) would bias the effect of the CVD-death variables on healthy eating towards zero. This implies that, if we suspect that there may be reporting bias, the estimated effect of the CVD-death variables can be treated as a lower bound of the true effect, thus strengthening the already highly significant intergenerational transmission results for females and possibly making a case for a weak intergenerational transmission for males.

We examined the effect of a number of additional interaction terms such as education, socioeconomic deprivation and other in order to trace other possible routes of intergenerational transmission, but none were found to be statistically significant.

\footnotetext{
${ }^{7}$ Regressions where the variable Income and its two interactions with parental CVD death have been replaced by the variable Social Deprivation and its two interactions with parental CVD death show that while both main variables are strongly significant, it is only the income interactions that are significant. Especially the comparison between the significance of the interaction term with income and the lack of significance of the similarly constructed term with socio-economic deprivation, is indicative of the role of income. ${ }^{7}$ Bad habits are clearly transmitted from mothers to daughters, but only influence current healthy eating where income is low. Social deprivation in itself reduces healthy eating, but its effect is not affected by the presence or absence of parental CVD death. Table A2 compares income and social deprivation results. Detailed estimation results are available upon request by the authors.
} 


\section{Conclusion}

This paper used data from the 2003 Scottish Health Survey in order to test the intergenerational transmission of healthy eating behaviour. The paper used multivariate regression in order to estimate the association between healthy eating and a number of covariates. It used observations on parental deaths from CVD as an approximation of an adverse health signal received by adult children and estimated their potential response in terms of their healthy eating behaviour by comparing adult children with and without the experience of a parental CVD death. The paper explained that if there is any compensatory eating behaviour, this would work in the direction of healthier eating amongst those with a parental CVD death. No such compensatory behaviour could be traced in the data. By contrast, the paper found that for some of the adult children a parental CVD death is associated with less healthy eating behaviour, which is dependent on gender and which was interpreted as an intergenerational transmission of unhealthy eating. The paper found that there is no transmission of any type from fathers to either their sons or their daughters, and no transmission from mothers to their sons. However, the paper found that daughters whose mothers died of CVD are more likely to be eating a less healthy diet themselves. The evidence is that there is an intergenerational transmission of unhealthy eating behaviour from mothers to daughters. This transmission was found to be weaker for adult children who live currently in households with higher than average income. Other pertinent factors such as education, employment status and social deprivation were found to not have an effect on the estimated intergenerational transmission.

The findings of the paper are important for preventive public health policy purposes as they expose a (readily observable) transmission route of (not easily observable) unhealthy eating habits at the individual level. The knowledge of this route can be used for the targeting of healthy eating interventions. By identifying the cause of death of the mother of females as a transmission route, and by showing that these intergenerational transmissions from mothers to daughters can be stronger amongst lower income households, the paper may assist in the earlier identification of specific groups of people at risk. As these adult children do not need to have had any medical problems themselves 
at the time they are being identified, early identification is feasible, before their unhealthy eating has had enough time to give them any strong health warnings, and, hopefully before their unhealthy eating habits have managed to cause serious and long-lasting health damage. 


\section{References}

Australian Social Trends 2001, Australian Bureau of Statistics Issue 4102.0.

Baker, C.W., M.A. Whisman \& K.D. Brownell, (2000). "Studying intergenerational transmission of eating attitudes and behaviours: Methodological and Conceptual Questions.” Health Psychology, Vol. 19, No 4, p.p. 376-381

Bantle C \& J.P. Haisken-DeNew, (2002). "Smoke signals: the intergenerational transmission of smoking behavior.” Discussion Papers 277, German Institute for Economic Research, Berlin.

Bateman I.J. \& A. Munro (2006). "Household versus individual valuation: What's the difference?” Discussion Paper No 06/02, Royal Holloway, University of London.

Billon S., A. Lluch, R. Gueguen, A.M. Berthier, G. Siest \& B.Herveth, (2002). "Family resemblance in breakfast energy intake: the Stanislas Family Study.” European Journal of Clinical Nutrition, Vol. 56, p.p. 1011-1019.

Bond S. \& J. Sales, (2001). "Household work in the UK: An analysis of the British Household Panel Survey.” Work Employment and Society, Vol. 15, Issue 02, p.p. 233250.

Brown R.\& J.Ogden, (2004). "Children's eating attitudes and behaviour: a study of the modelling and control theories of parental influence.” Health Education Research Vol. 19, No 3 p.p. 261-271.

Diabetes heartache: the hard reality of cardiovascular care for people with diabetes. Diabetes UK report, May 2007.

Farre L. and F. Vella, (2007). “The intergenerational Transmission of Gender Role Attitudes and its Implications for Female Labor Force Participation.” Discussion Paper No 2802, Institute for the Study of Labor (IZA), Bonn.

Frich J.C. L. Ose, K. Malterud \& P. Fugelli, (2006). "Perceived Vulnerability to Heart Disease in Patients with Familial hypercholesterolemia: A Qualitative Interview Study". Annals of Family Medicine May/June 2006, Vol. 4, No 3, p.p. 198-204, www.annfammed.org.

Hunt K., C. Davison, C. Emslie \& G. Ford, (2000). “Are perceptions of a family history of heart disease related to health-related attitudes and behaviour?” Health Education Research Theory and Practice Vol. 15, No 2, p.p. 131-143.

Kalesan B., J, Stine, A.J. Alberg (2006). “The joint influence of parental modeling and positive parental concern on cigarette smoking in middle and high school students.” The Journal of School Health, October 2006, Vol. 76, No 8, p.p.402-407. 
Kelly C. \& S.A. Stanner, (2003). "Diet and cardiovascular disease in the UK: are the messages getting across?” Proceedings of the Nutrition Society, Vol. 62, p.p. 583-589.

Liefbroer A.C. \& C.H. Elzinga, (2006). "Intergenerational Transmission of Behavioural Patterns: similarity of parents' and children's family life trajectories.” Draft Paper, Dept. of Social Research Methodology, Vrije Universiteit, Amsterdam.

Loureiro M.L., A. Sanz-de-Galdeano \& D. Vuri, (2006). "Smoking habits: Like father, like son, like Mother, like daughter.” Discussion Paper No 2279, Institute for the Study of Labor (IZA), Bonn.

Matteucci E., S. Passerai, M. Mariotti, F. Fagnani, I. Evangelista L. Rossi \& O. Giampeitro (2005). "Dietary habits and nutritional biomarkers in Italian type 1 diabetes families: evidence of unhealthy diet and combined-vitamin-deficient intakes." European Journal of Clinical Nutrition Vol. 59, p.p. 114-122.

McCusker ME Yoon PW Gwinn M Malarcher AM Neff L Khoury MJ. (2004). "Family history of heart disease and cardiovascular disease risk-reducing behaviours". Genetics in Medicine, May/June 2004, Vol. 6, No 3, p.p. 153-158.

Patrick H. \& T.A. Nicklas, (2005). "A review of family and social determinants of children's eating patterns and diet quality." Journal of the American College of Nutrition Vol. 24, No 2, p.p. 83-92.

Renehan A. \& A. Howell, (2005). "Preventing cancer, cardiovascular disease, and diabetes.” The Lancet, Vol. 365, Issue 9469, p.p. 1449-1451.

Szabo E., V. White \& J. Hayman, (2006). "Can home smoking restrictions influence adolescents' smoking behaviours if their parents and friends smoke?” Addictive Behaviours, Vol. 31, p.p. 2298-2303.

Tiggemann M. \& J. Lowes, (2002). "Predictors of maternal control over children's eating behaviour”. Research Report Appetite, Vol. 39, p.p. 1-7.

Walter F.M., J. Emery, D. Braithwaite T.M. Marteau, (2004). "Lay understanding of familial risk of common chronic diseases: a systematic review and synthesis of qualitative research.” Annals of Family Medicine Annals of Family Medicine, November/December 2004, Vol. 2, No 6, p.p. 583-594, www.annfammed.org.

Wardle J., C Guthrie, S Sanderson, L Birch and R Plomin, (2001). "Food and activity preferences in children of lean and obese parents". International Journal of Obesity, Vol. 25, p.p. 971-977. 
Watt G., A. McConnachie, M. Upton, C. Emslie \& K. Hunt, (2000). «How accurately do adult sons and daughters report and perceive parental deaths from coronary disease?" Journal of Epidemiology and Community Health, Vol. 54, p.p. 859-863.

Wen C.P., S.P. Tsai, T.Y. Cheng, C.C. Hsu, T. Chen \& H.S. Lin (2005). "Role of parents and peers in influencing the smoking status of high school students in Taiwan.” Tobacco Control, Vol. 14 (Supplement 1), p.p. i10-i15. 


\section{Appendix}

\section{Description of Variables}

Paternal and Maternal death from CVD - CVDFA; (1=father died from CVD, $0=$ nonCVD death or no paternal death), CVDMO (1=mother died from CVD, $0=$ non-CVD death or no maternal death). CVDFA and CVDMO derived from conspab and consmab, respectively (Categories 1-6: hypertension, angina, myocardial infarction, stroke, other heart trouble and diabetes. Category 7: death but none of the above conditions). A third dummy was created: NODEATH (1=no parental death).

Age - five dummy age groups: age16-24, age25-34, age 35-44, age 45-54 and age 55-64. Reference category: age16-24

Gender - gender: female $=0$, male $=1$

Education (highest qualification achieved) - five dummy variables: DEGPROF (university degree/professional qualification); UPMIDED (City \& Guilds, HND or equivalent); LOWMIDED (A level, Scottish Higher Grad or equivalent vocational qualification); lowed ('O’ level, Standard Grade or equivalent vocational qualification); and, NOED(none of the above qualifications). Reference category: NOED Number of children (continuous variable) - NCHILD (number of infants and children currently in household)

Employment - EMPLOYMENT: Not in paid employment=0, In paid employment=1 Smoking - 3 dummy variables: NEVERSM (1=have never smoked); EXSM (1=exsmoker); and, SMOKER (1=currently smoking more than 0 cigarettes a day). Reference category: SMOKER.

Alcohol consumption - 3 dummy variables: OCCNEVDR (1=drink occasionally or never drink); REGDROVLIM (1= drink regularly, over the recommended amount); and REDRUNLIM (1= drink regularly, below the recommended amount). Reference category: REDRUNLIM

Self reported general health status - NGENHELF $(1-4,1=$ very good, 2= good, $3=$ fair and 4=bad/very bad). The variable GENHELF was collapsed from 5 to 4 categories due to small numbers in categories 4 and 5 of GENHELF. 
Marital status - 3 dummy variables: MARR_COHAB (1=married or cohabiting); DIVWSEP ( $1=$ divorced, widowed or separated); and SINGLE (1=single). Reference category: SINGLE.

Physical activity - NHRSTOT (a continuous variable of average number of hours of physical activity per week (walking, sports, manual activity(not work related) and housework) weighted by intensity of physical activity (heavy, moderate or light) and level of activity the individual does at work and if such activity is part or full time). Household Income - INCOME. Continuous variable. Equivalised household income. 
TABLE A1: Descriptive statistics

\begin{tabular}{|c|c|c|c|c|c|c|c|c|}
\hline & \multicolumn{4}{|c|}{ Full sample } & \multicolumn{4}{|c|}{ Reduced sample } \\
\hline & \multicolumn{2}{|c|}{ Men } & \multicolumn{2}{|c|}{ Women } & \multicolumn{2}{|c|}{ Men } & \multicolumn{2}{|c|}{ Women } \\
\hline & Mean. & $\begin{array}{l}\text { Standard } \\
\text { Deviation }\end{array}$ & Mean. & $\begin{array}{l}\text { Standard } \\
\text { Deviation }\end{array}$ & Mean. & $\begin{array}{l}\text { Standard } \\
\text { Deviation }\end{array}$ & Mean. & $\begin{array}{l}\text { Standard } \\
\text { Deviation }\end{array}$ \\
\hline $\begin{array}{l}\text { Healthy Eating } \\
\text { Score }\end{array}$ & 17.126 & 4.983 & 18.402 & 4.805 & 17.957 & 4.899 & 19.052 & 4.744 \\
\hline \multicolumn{9}{|c|}{ Age group (reference category age less than 25) } \\
\hline 25 to 34 & 0.166 & - & 0.180 & - & 0.055 & - & 0.058 & - \\
\hline 35 to 44 & 0.267 & - & 0.256 & - & 0.215 & - & 0.222 & - \\
\hline 45 to 54 & 0.224 & - & 0.237 & - & 0.323 & - & 0.334 & - \\
\hline 55 to 64 & 0.223 & - & 0.214 & - & 0.389 & - & 0.373 & - \\
\hline \multicolumn{9}{|c|}{ Education (Reference category lowest education) } \\
\hline Higher & 0.250 & - & 0.267 & - & 0.239 & - & 0.251 & - \\
\hline Upper-middle & 0.210 & - & 0.103 & - & 0.214 & - & 0.085 & - \\
\hline Lower-middle & 0.105 & - & 0.138 & - & 0.071 & - & 0.101 & - \\
\hline Low & 0.180 & - & 0.221 & - & 0.119 & - & 0.171 & - \\
\hline \multicolumn{9}{|l|}{ Family } \\
\hline Dep. children & 0.580 & 0.937 & 0.662 & 0.974 & 0.439 & 0.848 & 0.448 & 0.858 \\
\hline \multicolumn{9}{|c|}{ Marital status (Reference category single) } \\
\hline $\begin{array}{l}\text { Married or co- } \\
\text { hab }\end{array}$ & 0.689 & - & 0.643 & - & 0.783 & - & 0.701 & - \\
\hline $\begin{array}{l}\text { Divorced or } \\
\text { sep. }\end{array}$ & 0.080 & - & 0.159 & - & 0.104 & - & 0.202 & - \\
\hline \multicolumn{9}{|l|}{ Economic status } \\
\hline $\begin{array}{l}\text { In } \\
\text { Employment }\end{array}$ & 0.731 & - & 0.621 & -- & 0.704 & - & 0.585 & - \\
\hline $\begin{array}{l}\text { Household } \\
\text { income }\end{array}$ & 26.621 & 21.448 & 24.332 & 20.269 & 25.828 & 20.170 & 23.545 & 20.696 \\
\hline \multicolumn{9}{|c|}{ Health and Lifestyles: } \\
\hline \multicolumn{9}{|c|}{ Smoking (reference category smoker) } \\
\hline Never Smoked & 0.439 & - & 0.449 & - & 0.397 & - & 0.419 & - \\
\hline Ex-smoker & 0.240 & - & 0.241 & - & 0.290 & - & 0.273 & - \\
\hline \multicolumn{9}{|c|}{ Alcohol drinking (reference category regular drinking below the limit) } \\
\hline $\begin{array}{l}\text { Regular over } \\
\text { limit }\end{array}$ & 0.286 & - & 0.165 & - & 0.276 & - & 0.146 & - \\
\hline No alcohol & 0.280 & - & 0.418 & - & 0.272 & - & 0.420 & - \\
\hline $\begin{array}{l}\text { Physical } \\
\text { Activity }\end{array}$ & 7.816 & - & 5.442 & - & 7.474 & - & 5.466 & - \\
\hline General Health & 1.936 & 0.910 & 1.940 & 0.887 & 2.072 & 0.978 & 2.056 & 0.937 \\
\hline \multicolumn{9}{|c|}{ Parental CVD death } \\
\hline Father died & 0.204 & - & 0.205 & - & 0.376 & - & 0.377 & - \\
\hline Mother died & 0.148 & - & 0.136 & - & 0.272 & - & 0.250 & - \\
\hline Sample size & 2161 & - & 2630 & - & 1174 & - & 1430 & - \\
\hline
\end{tabular}


TABLE A2: Healthy Eating regression results with Income interaction terms

\begin{tabular}{|c|c|c|c|c|c|c|c|c|}
\hline & \multicolumn{4}{|c|}{ Full sample } & \multicolumn{4}{|c|}{ Reduced sample } \\
\hline & \multicolumn{2}{|c|}{ Men } & \multicolumn{2}{|c|}{ Women } & \multicolumn{2}{|c|}{ Men } & \multicolumn{2}{|c|}{ Women } \\
\hline & Coeff. & t-ratio & Coeff. & t-ratio & Coeff. & t-ratio & Coeff. & t-ratio \\
\hline Constant & 11.96 & 23.62 & 13.78 & 30.77 & 11.72 & 10.37 & 15.43 & 13.89 \\
\hline \multicolumn{9}{|c|}{ Age group (reference category age less than 25) } \\
\hline 25 to 34 & 2.10 & 5.07 & 1.05 & 2.89 & 1.81 & 1.57 & -0.48 & -0.44 \\
\hline 35 to 44 & 3.39 & 8.27 & 1.92 & 5.39 & 2.62 & 2.51 & 0.49 & 0.48 \\
\hline 45 to 54 & 4.22 & 9.39 & 3.14 & 8.42 & 3.71 & 3.51 & 1.49 & 1.49 \\
\hline 55 to 64 & 5.29 & 10.87 & 4.23 & 10.42 & 4.84 & 4.49 & 2.69 & 2.63 \\
\hline \multicolumn{9}{|c|}{ Education (Reference category lowest education) } \\
\hline Higher & 2.95 & 9.80 & 3.16 & 12.39 & 2.26 & 5.69 & 3.20 & 10.30 \\
\hline Upper-middle & 1.43 & 4.85 & 2.23 & 6.78 & 1.05 & 2.82 & 1.95 & 4.37 \\
\hline Lower-middle & 1.59 & 4.39 & 1.65 & 5.53 & 0.69 & 1.24 & 1.54 & 3.80 \\
\hline Low & 0.63 & 1.94 & 0.75 & 2.90 & 0.78 & 1.60 & 1.18 & 3.35 \\
\hline \multicolumn{9}{|l|}{ Family } \\
\hline Dep. children & -0.05 & -0.45 & -0.29 & -2.83 & 0.06 & 0.33 & -0.34 & -2.19 \\
\hline Married or co-hab & -0.21 & -0.69 & 0.76 & 2.87 & -0.37 & -0.77 & 0.84 & 2.08 \\
\hline Divorced or sep. & 0.24 & 0.52 & 0.85 & 2.66 & 0.26 & 0.41 & 0.85 & 1.88 \\
\hline \multicolumn{9}{|l|}{ Economic status } \\
\hline In Employment & -0.69 & -2.68 & -0.59 & -3.00 & -0.48 & -1.35 & -0.57 & -2.12 \\
\hline Household income & 0.02 & 3.41 & 0.02 & 3.55 & 0.03 & 2.77 & 0.01 & 1.98 \\
\hline \multicolumn{9}{|l|}{ Health and Lifestyles: } \\
\hline \multicolumn{9}{|c|}{ Smoking (reference category never smoked) } \\
\hline Never Smoked & 1.22 & 5.18 & 1.22 & 5.78 & 1.91 & 5.52 & 1.52 & 5.15 \\
\hline Ex-smoker & 1.82 & 6.63 & 1.34 & 5.62 & 1.91 & 5.32 & 1.35 & 4.20 \\
\hline \multicolumn{9}{|c|}{ Alcohol drinking (reference category regular drinking below the limit) } \\
\hline Regular over limit & -0.19 & -0.84 & 0.00 & -0.01 & -0.32 & -0.98 & -0.59 & -1.71 \\
\hline No alcohol & -0.78 & -3.24 & -0.92 & -5.01 & -0.75 & -2.23 & -1.05 & -4.23 \\
\hline Physical Activity & 0.04 & 4.05 & 0.06 & 5.24 & 0.05 & 3.17 & 0.05 & 3.18 \\
\hline General Health & -0.24 & -2.02 & -0.22 & -2.01 & -0.05 & -0.32 & -0.26 & -1.85 \\
\hline \multicolumn{9}{|l|}{ Parental CVD death } \\
\hline Father CVD-death & 0.56 & 1.17 & 0.35 & 1.12 & 0.71 & 1.39 & 0.26 & 0.79 \\
\hline Mother CVD-death & 0.40 & 0.82 & -1.22 & -2.98 & 0.42 & 0.82 & -1.29 & -3.05 \\
\hline \multicolumn{9}{|c|}{ CVD-death $\times$ Household Income } \\
\hline Fa-CVD $\times$ Income & -0.01 & -0.76 & -0.01 & -1.23 & -0.02 & -1.11 & 0.00 & -0.50 \\
\hline Mo-CVD×Income & -0.01 & -0.36 & 0.02 & 1.73 & -0.01 & -0.34 & 0.03 & 1.94 \\
\hline R-square & 0.2 & & 0.2 & 23 & 0.1 & & 0.2 & 367 \\
\hline Sample size & 21 & & 26 & & 11 & & 14 & \\
\hline
\end{tabular}


TABLE A3: Comparing Household Income and Social Deprivation results

\begin{tabular}{|c|c|c|c|c|c|c|c|c|}
\hline & \multicolumn{4}{|c|}{$\begin{array}{l}\text { Model 2: with an income } \\
\text { interaction term }\end{array}$} & \multicolumn{4}{|c|}{$\begin{array}{c}\text { Model 3: with a social deprivation } \\
\text { interaction term }\end{array}$} \\
\hline & \multicolumn{2}{|c|}{ Full sample } & \multicolumn{2}{|c|}{ Reduced sample } & \multicolumn{2}{|c|}{ Full sample } & \multicolumn{2}{|c|}{ Reduced sample } \\
\hline & Men & Women & Men & Women & Men & Women & Men & Women \\
\hline Household Income & $\begin{array}{c}0.02 \\
(3.41)\end{array}$ & $\begin{array}{c}0.02 \\
(3.55)\end{array}$ & $\begin{array}{c}0.03 \\
(2.77)\end{array}$ & $\begin{array}{c}0.01 \\
(1.98)\end{array}$ & - & - & - & - \\
\hline Social deprivation & - & - & - & - & $\begin{array}{c}0.32 \\
(4.05)\end{array}$ & $\begin{array}{c}0.33 \\
(4.78)\end{array}$ & $\begin{array}{c}0.31 \\
(2.34)\end{array}$ & $\begin{array}{c}0.28 \\
(2.61)\end{array}$ \\
\hline Father CVD-death & $\begin{array}{c}0.56 \\
(1.17)\end{array}$ & $\begin{array}{c}0.35 \\
(1.12)\end{array}$ & $\begin{array}{c}0.71 \\
(1.39)\end{array}$ & $\begin{array}{c}0.26 \\
(0.79)\end{array}$ & $\begin{array}{l}-0.17 \\
(-0.31)\end{array}$ & $\begin{array}{l}-0.01 \\
(-0.02)\end{array}$ & $\begin{array}{l}-0.21 \\
(-0.33)\end{array}$ & $\begin{array}{c}-0.06 \\
(-0.11)\end{array}$ \\
\hline Mother CVD-death & $\begin{array}{c}0.40 \\
(0.82)\end{array}$ & $\begin{array}{l}-1.22 \\
(-2.98)\end{array}$ & $\begin{array}{c}0.42 \\
(0.82)\end{array}$ & $\begin{array}{l}-1.29 \\
(-3.05)\end{array}$ & $\begin{array}{c}0.51 \\
(0.83)\end{array}$ & $\begin{array}{c}-0.93 \\
(-1.69)\end{array}$ & $\begin{array}{c}0.33 \\
(0.49)\end{array}$ & $\begin{array}{c}-0.93 \\
(-1.60)\end{array}$ \\
\hline $\begin{array}{l}\text { Income*Mother } \\
\text { CVD-death }\end{array}$ & $\begin{array}{l}-0.005 \\
(-0.36)\end{array}$ & $\begin{array}{l}0.022 \\
(1.73)\end{array}$ & $\begin{array}{l}-0.005 \\
(-0.34)\end{array}$ & $\begin{array}{l}0.026 \\
(1.94)\end{array}$ & - & - & - & - \\
\hline $\begin{array}{l}\text { Income*Father } \\
\text { CVD-death }\end{array}$ & $\begin{array}{l}-0.012 \\
(-0.76)\end{array}$ & $\begin{array}{l}-0.009 \\
(-1.23)\end{array}$ & $\begin{array}{l}-0.019 \\
(-1.11)\end{array}$ & $\begin{array}{l}-0.004 \\
(-0.50)\end{array}$ & - & - & - & - \\
\hline $\begin{array}{l}\text { Social Deprivation } \\
* \text { Mother CVD-death }\end{array}$ & - & - & - & - & $\begin{array}{l}-0.14 \\
(-0.76)\end{array}$ & $\begin{array}{c}0.87 \\
(0.55)\end{array}$ & $\begin{array}{l}-0.07 \\
(-0.34)\end{array}$ & $\begin{array}{c}0.10 \\
(0.58)\end{array}$ \\
\hline $\begin{array}{l}\text { Social Deprivation } \\
\text { *Father CVD-death }\end{array}$ & - & - & - & - & $\begin{array}{c}0.12 \\
(0.72)\end{array}$ & $\begin{array}{c}0.60 \\
(0.42)\end{array}$ & $\begin{array}{c}0.13 \\
(0.73)\end{array}$ & $\begin{array}{c}0.09 \\
(0.56)\end{array}$ \\
\hline Sample size & 2161 & 2630 & 1174 & 1430 & 2420 & 2962 & 1310 & 1624 \\
\hline R-square & 0.2341 & 0.2523 & 0.1766 & 0.2367 & 0.2335 & 0.2599 & 0.1772 & 0.2353 \\
\hline
\end{tabular}

